Article

\title{
Oxidative desulfurization of dibenzothiophene catalyzed by peroxotungstate on functionalized MCM-41 materials using hydrogen peroxide as oxidant
}

\author{
Dong Xie, Qihui He, Yangyang Su, Tongwei Wang, Renfu Xu, Baixing $\mathrm{Hu}$ * \\ Jiangsu Key Laboratory of Vehicle Emissions Control, and School of Chemistry and Chemical Engineering, Nanjing University, Nanjing 210093, Jiangsu, \\ China
}

A R T I C L E I N F O

Article history:

Received 29 January 2015

Accepted 20 May 2015

Published 20 August 2015

Keywords:

Dibenzothiophene

Oxidative desulfurization

Peroxotungstate

MCM-41

\begin{abstract}
A B S T R A C T
Catalysts play an important role in oxidative desulfurization, a promising process for producing cleaner fossil fuels for transport. A highly efficient catalyst, $\mathrm{Q}_{4}-\mathrm{H}_{2} \mathrm{Se}^{\mathrm{IV}}{ }_{3} \mathrm{~W}_{6}$, for the oxidative desulfurization of dibenzothiophene (DBT) was reported in 2011. To comprehensively evaluate this catalyst and better understand its recovery, two types of the catalyst were prepared by impregnating $\mathrm{Q}_{4}-\mathrm{H}_{2} \mathrm{Se}^{\mathrm{IV}} 3 \mathrm{~W}_{6}$ on MCM-41 and functionalized MCM-41 materials. In the oxidative desulfurization process catalyzed by these supported catalysts, the conversion of DBT reached $98.7 \%$. The catalytic activities were excellent when $\mathrm{Q}_{4}-\mathrm{H}_{2} \mathrm{Se}^{\mathrm{IV}} 3 \mathrm{~W}_{6}$ was impregnated on functionalized MCM-41. The results showed that the supported catalysts had excellent reusability. In addition, a mechanism for the catalytic oxidative desulfurization was proposed.
\end{abstract}

(C) 2015, Dalian Institute of Chemical Physics, Chinese Academy of Sciences. Published by Elsevier B.V. All rights reserved.

\section{Introduction}

Globally, crude oil continues to be a widely used and important resource, particularly, for transportation fuels [1-3]. However, crude oil-derived fuels contain a complex range of components, which themselves include various sulfur compounds. As well as deactivating catalysts that are fitted to automotive exhausts to decrease pollutant emissions, combustion of these sulfur compounds releases pollutants that contribute to acid rain $[4,5]$. Increasing environmental protection awareness has therefore led to an urgent need for fuel desulfurization $[6,7]$. Many countries have issued environmental regulations to limit fuel-sulfur concentrations to less than 10 ppm [8]. However, achieving such low concentrations with the range of complicated sulfur compounds found in petroleum makes refining more challenging $[2,9]$.
At present, the removal of sulfur compounds from liquid fuels is achieved by hydrodesulfurization that can remove thiols, sulfides, and disulfides efficiently $[10,11]$. However, hydrodesulfurization is a nonselective hydrogenation process that requires high temperature and high pressure. The process also lowers the fuel's octane level and requires substantial quantities of $\mathrm{H}_{2}$, which is expensive [12]. Furthermore, hydrodesulfurization is a less successful method for achieving desulfurization of thiophene and benzothiophene derivatives [13-15]. Therefore, for the production of cleaner transportation fuels, supplementary approaches to achieve this deep desulfurization are required.

A number of deep desulfurization approaches have been investigated, including biodesulfurization, extractive desulfurization by ionic liquid, adsorptive desulfurization, and oxidative desulfurization [16-21]. Among them, the oxidative desulfuri-

\footnotetext{
* Corresponding author. Tel/Fax: +86-25-83592878; E-mail: hubx@nju.edu.cn This work was supported by the National Science Fund for Talent Training in Basic Science (J1103310). 


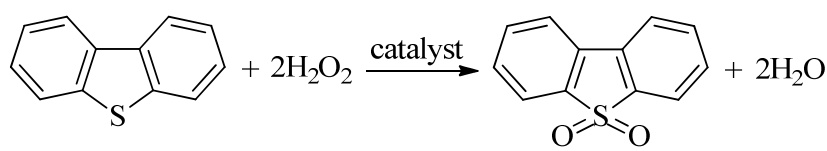

Scheme 1. Example of the oxidative desulfurization process.

zation is considered one of the most effective methods [22-27]. This is because in the oxidative desulfurization process dibenzothiophene (DBT) and its derivatives can be selectively oxidized to their corresponding sulfoxides and sulfones (Scheme 1) under mild reaction conditions $(<373 \mathrm{~K}$ and ambient pressure) using common and inexpensive oxidants [28,29]. The sulfoxides and sulfones can then be easily removed using water-soluble polar solvents as the extractant $[8,24]$.

The oxidant plays a very important role in the oxidative desulfurization process. Many types of oxidants have been studied, such as $\mathrm{O}_{2}, \mathrm{H}_{2} \mathrm{O}_{2}$, and organic peroxides. Among them, $\mathrm{H}_{2} \mathrm{O}_{2}$ has been widely used as it is cheap, commercially available, and relatively environmentally friendly [30-33].

Catalysts are responsible for activating the oxidants and are therefore essential in the oxidative desulfurization process [34]. Different catalytic systems have been reported for the process; these include those based on an organic acid [35], heteropolyoxometalates [36], an ionic liquid [37], a molecular sieve [38], and photocatalysts [39]. Within this group, polyoxometalates have a number of unique features that allow their processes to exhibit higher sulfur removal efficiencies [40,41].

In recent years, supporting catalysts on solid mesoporous materials have been reported as a potential solution to deep desulfurization. Li et al. [42] reported a mesoporous silicate incorporated with phosphotungstic acid for DBT oxidation that obtained 98\%-99\% DBT conversion in experiments with model oil. In another experiment, Li et al. [43] prepared molybdovanadophosphoric acid on functionalized SBA-15 for oxidative desulfurization and reported a 97.8\% conversion of DBT in a model oil while the supported catalyst was shown to be easily recovered; an important finding given that catalyst recovery and recycling is now a significant focus of the catalytic industry. The same work also noted that immobilization of the catalyst on mesoporous materials with weak bonding led to partial leaching when reacted in a polar solvent [43]. However, this and a number of other works have shown that when the catalyst is supported on modified silica materials with electrostatic interactions it exhibits better stability [43-45].

In 2011 , the catalyst used in this work $\left(\mathrm{Q}_{4}-\mathrm{H}_{2} \mathrm{Se}^{\mathrm{IV}} \mathrm{W}_{6}\right)$ was reported to exhibit highly efficient and selective properties in the oxidative desulfurization process with DBT conversion of more than $99 \%$ in a desulfurization test using model oil [46] However, catalyst recovery in this case remains an unresolved topic and is the focus of this work.

Here, an optimized approach is reported whereby the peroxotungstate catalyst was impregnated in MCM-41 and MCM-41- $\mathrm{NH}_{2}$ (functionalized by 3-aminopropyltriethoxysilane (APTES)) materials. The ability of these materials to facilitate the oxidative desulfurization process was tested using a model oil. The optimum reaction conditions were investigated, including reaction time, reaction temperature, molar ratio of
$[0] /[S]$, and dosage of catalyst. In addition, recycling tests were carried out.

\section{Experimental}

\subsection{Materials}

DBT (99\%), APTES, sodium tungstate dihydrate (AR), cetyltrimethylammonium bromide (CTABr), selenium dioxide (AR), typical tetraethyl orthosilicate (TEOS), and stearyl trimethyl ammonium chloride (STAC, 99\%) were purchased from Aladdin Reagent Inc. $\mathrm{H}_{2} \mathrm{O}_{2}(30 \%, \mathrm{AR})$ and $n$-octane (CP) were obtained from Sinopharm Chemical Reagent Co. Ltd. $\mathrm{NaOH}$ (AR), chloroform (AR), acetonitrile (AR), toluene (AR), and $\mathrm{HCl}$ (37\%, AR) were supplied by Nanjing Chemical Reagent Co. Ltd. All of the reagents except toluene were used as received without any further purification. The toluene was distilled to remove water and sealed in bottles to keep it dry.

The model fuels were prepared by dissolving DBT in $n$-octane to obtain three solutions with a sulfur content of 200 , 500 , and 800 ppm, respectively.

\subsection{Synthesis of $M C M-41$ and $M C M-41-N_{2}$}

MCM-41 was synthesized following the procedures described in the literature [47-49]. In brief, this involved TEOS slowly being added to a vigorously stirred solution of $\mathrm{NaOH}$ and $\mathrm{CTABr}$ at room temperature. The solution was then stirred for $2 \mathrm{~h}$ at $353 \mathrm{~K}$. Heating was stopped though stirring continued until the temperature had cooled to room temperature. The obtained gel was crystallized at $383 \mathrm{~K}$ for $48 \mathrm{~h}$ in stainless steel reactors with Teflon liners. After filtration, the crystallized gel was calcined in a muffle furnace at $823 \mathrm{~K}$ for $5 \mathrm{~h}$ and allowed to cool naturally yielding MCM-41 as a white powder.

MCM-41- $\mathrm{NH}_{2}$ was prepared using a grafting technique [50]. Here, MCM-41 was first activated in a muffle furnace at $773 \mathrm{~K}$ for $4 \mathrm{~h}$ and cooled in a vacuum oven. One gram of activated MCM-41 was then dispersed in $50 \mathrm{~mL}$ of distilled toluene, and $1.5 \mathrm{~g}$ of APTES was added to the mixture. The mixture was magnetically stirred and refluxed at room temperature for $8 \mathrm{~h}$. The resultant white solid was filtered and washed with distilled toluene. MCM-41- $\mathrm{NH}_{2}$ powder was obtained after the white solid had been dried under vacuum at $303 \mathrm{~K}$ for $8 \mathrm{~h}$.

\subsection{Preparation of catalysts}

Catalyst A, $\left[\mathrm{C}_{18} \mathrm{H}_{37} \mathrm{~N}\left(\mathrm{CH}_{3}\right)_{3}\right]_{4}\left[\mathrm{H}_{2} \mathrm{Se}^{\mathrm{IV}}{ }_{3} \mathrm{~W}_{6} \mathrm{O}_{34}\right]$ (abbreviated to $\mathrm{Q}_{4}-\mathrm{H}_{2} \mathrm{Se}^{\mathrm{IV}} \mathrm{V}_{3} \mathrm{~W}_{6}$ ), was synthesized according to the method described in the literature [46]. A yellow flaky solid was obtained after the crude product had been dried at room temperature under vacuum overnight.

Catalyst B, MCM-41/Q $\mathrm{Q}_{4}-\mathrm{H}_{2} \mathrm{Se}^{\mathrm{IV}} \mathrm{W}_{3} \mathrm{~W}_{6}$, was prepared by the wet impregnation method [42]. A desired amount of $\mathrm{Q}_{4}-\mathrm{H}_{2} \mathrm{Se}^{\mathrm{IV}} \mathrm{W}_{3}$ was weighed and dissolved into an aqueous solution, and a calculated amount of MCM-41 was added to the solution. As previously reported [51], to ensure that the peroxotungstate retains its structure and is well dispersed on MCM-41 materi- 
als, the peroxotungstate content should be lower than the amount required for monolayer coverage. Therefore, a loading of $5 \mathrm{wt} \%$ was chosen. To prepare $5 \mathrm{wt} \% \mathrm{MCM}-41 / \mathrm{Q}_{4}-\mathrm{H}_{2} \mathrm{Se}$ $\mathrm{IV}_{3} \mathrm{~W}_{6}, 0.020 \mathrm{~g} \mathrm{Q}_{4}-\mathrm{H}_{2} \mathrm{Se}^{\mathrm{IV}} \mathrm{W}_{6}, 1.550 \mathrm{~g}$ of deionized water, and $0.389 \mathrm{~g}$ of MCM-41 were mixed in a beaker with the mixture then continuously stirred overnight at room temperature. To activate $\mathrm{MCM}-41 / \mathrm{Q}_{4}-\mathrm{H}_{2} \mathrm{Se}^{\mathrm{IV}}{ }_{3} \mathrm{~W}_{6}$, the impregnated materials were placed into a vacuum oven for $12 \mathrm{~h}$ at $383 \mathrm{~K}$.

Catalyst C, MCM-41-NH2 $/ \mathrm{Q}_{4}-\mathrm{H}_{2} \mathrm{Se}^{\mathrm{IV}} \mathrm{W}_{3}$, was prepared following a similar method as that used for catalyst $\mathrm{B}$. To prepare 5 wt $\%$ MCM-41-NH $\mathrm{N}_{2} / \mathrm{Q}_{4}-\mathrm{H}_{2} \mathrm{Se}^{\mathrm{IV}} 3 \mathrm{~W}_{6}, 0.020 \mathrm{~g}$ of $\mathrm{Q}_{4}-\mathrm{H}_{2} \mathrm{Se}^{\mathrm{IV}}{ }_{3} \mathrm{~W}_{6}$, $2.680 \mathrm{~g}$ of deionized water, and $0.420 \mathrm{~g}$ of $\mathrm{MCM}-41-\mathrm{NH}_{2}$ were mixed. Prior to use, the sample was heated overnight in a vacuum oven at $383 \mathrm{~K}$ to remove gas or water trapped in the sample.

\subsection{Characterization of samples}

Fourier transform infrared spectra (FTIR) in the range of $500-4000 \mathrm{~cm}^{-1}$ were obtained using a NEXUS 870 spectrometer (Nicolet, America) using a dried $\mathrm{KBr}$ pellet.

$\mathrm{X}$-ray diffraction (XRD) measurements were carried out from $0.6^{\circ}$ to $10^{\circ}$ with a scan rate of $0.5^{\circ} / \mathrm{min}$ using a D8 ADVANCE system using a $\mathrm{Cu} K \alpha$ radiation source at $40 \mathrm{kV}$ and $40 \mathrm{~mA}$.

Images of the samples were captured by transmission electron microscopy (TEM), which was carried out using a JEOL 2100 electron microscope operating at $200 \mathrm{kV}$.

$\mathrm{N}_{2}$ adsorption-desorption isotherms were measured by an ASAP 2020 (Micromeritics). The samples were pretreated at $473 \mathrm{~K}$ under a high vacuum, and the pore structure was calculated from the adsorption isotherm. Specific surface areas were calculated in accordance with the BET method and pore size distributions were calculated using the desorption branch of the isotherm and employing the BJH method.

\subsection{Oxidative desulfurization of DBT}

In a $50 \mathrm{~mL}$ round-bottom flask equipped with a magnetic stirrer and a heated circulating bath, $0.5 \mathrm{~mL}$ of acetonitrile was mixed with $10 \mathrm{~mL}$ of DBT, the model fuel, to be tested. Acetonitrile was used as it is one of the most suitable solvents for the oxidation desulfurization system [52-54]. The amount of catalyst was maintained at a molar ratio of catalyst $/ \mathrm{DBT}=1: 60$ [46]. Following the reaction detailed in Scheme 1, the amount of $\mathrm{H}_{2} \mathrm{O}_{2}$ (30 wt\%) required was determined by maintaining $[0] /[\mathrm{S}]=2: 1$. After the catalyst and $\mathrm{H}_{2} \mathrm{O}_{2}$ were added, the reaction was started at atmospheric pressure and a given set temperature that depended on the test with the reaction time then recorded.

The progress of oxidation was promptly analyzed by a sulfur-specific gas chromatography system that was equipped with a flame photometric detector (GC-FPD). The specimens were sampled from the supernatant liquid at different time intervals. The GC-FPD was set as follows: capillary column SE-30 $(50 \mathrm{~mm} \times 0.53 \mathrm{~mm} \times 0.5 \mu \mathrm{m})$; injector temperature 513 $\mathrm{K}$; column temperature $453 \mathrm{~K}$; detector temperature $493 \mathrm{~K}$; ultra-pure $\mathrm{N}_{2}$ as carrier gas $(1.0 \mathrm{~mL} / \mathrm{min})$; reagent gases air (60 $\mathrm{mL} / \mathrm{min})$ and ultra-pure $\mathrm{H}_{2}(60 \mathrm{~mL} / \mathrm{min})$; injection volume $1 \mu \mathrm{l}$. Confidence in measurements repeatability was ensured by repeating each measurement three times.

The DBT conversion $(D)$ was calculated as $D=\left(S_{0}-S_{\mathrm{F}}\right) / S_{0} \times$ $100 \%$, where $S_{0}$ and $S_{\mathrm{F}}$ are the concentration of sulfur (DBT) in the oil phase initially and after the reaction had completed, respectively.

\section{Results and discussion}

\subsection{Catalyst characteristics}

The FTIR spectrum of $\mathrm{Q}_{4}-\mathrm{H}_{2} \mathrm{Se}^{\mathrm{IV}} \mathrm{W}_{6}$ (catalyst $\mathrm{A}$ ) is shown in Fig. 1(1) and exhibits characteristic peaks at $969 \mathrm{~cm}^{-1}(\mathrm{~W}=0$ stretching vibration), $911 \mathrm{~cm}^{-1}$ (0-0 stretching vibration), and $721 \mathrm{~cm}^{-1}$ (Se-0 stretching vibration). Fig. 1(2)-(5) shows the FTIR spectra of MCM-41, MCM-41/ $\mathrm{Q}_{4}-\mathrm{H}_{2} \mathrm{Se}^{\mathrm{IV}} \mathrm{W}_{3} \mathrm{~W}_{6}$ (catalyst B), MCM-41- $\mathrm{NH}_{2}$, and MCM-41- $\mathrm{NH}_{2} / \mathrm{Q}_{4}-\mathrm{H}_{2} \mathrm{Se}^{\mathrm{IV}} \mathrm{W}_{6}$ (catalyst C). The peaks at 780 and $1090 \mathrm{~cm}^{-1}$ are associated with the $\mathrm{Si}-\mathrm{O}-\mathrm{Si}$ symmetric and asymmetric stretching vibrations of mesoporous silica, respectively. The band at $780 \mathrm{~cm}^{-1}$ is assigned to the stretching vibration of $\mathrm{Si}-\mathrm{O}-\mathrm{H}$. The peak at $721 \mathrm{~cm}^{-1}$ shifted to $696 \mathrm{~cm}^{-1}$ after $\mathrm{Q}_{4}-\mathrm{H}_{2} \mathrm{Se}^{\mathrm{IV}_{3} \mathrm{~W}_{6}}$ was impregnated on MCM-41 and MCM-41-NH2. Significantly, compared with MCM-41 and MCM-41- $\mathrm{NH}_{2}$, a new band appeared at approximately 1470 $\mathrm{cm}^{-1}$ over catalyst $\mathrm{B}$ and catalyst $\mathrm{C}$. These results indicate that $\mathrm{Q}_{4}-\mathrm{H}_{2} \mathrm{Se}^{\mathrm{IV}} 3 \mathrm{~W}_{6}$ was highly dispersed on the surface of MCM-41 and MCM-41- $\mathrm{NH}_{2}$.

Small-angle XRD patterns of four samples are depicted in Fig. 2. Both MCM-41 and MCM-41- $\mathrm{NH}_{2}$ exhibited a strong reflection at $2 \theta=2.1^{\circ}$ because of the (100) plane and a few weak peaks because of (110) and (200) plane reflections. These peaks show highly ordered, two-dimensional, hexagonal and mesoporous channels of MCM-41 and MCM-41-NH2. For catalysts $\mathrm{B}$ and $\mathrm{C}$, all of these peaks were still detected but with a decreased intensity. This indicates that the ordered pore structure of mesoporous materials was retained well and that the $\mathrm{Q}_{4}-\mathrm{H}_{2} \mathrm{Se}^{\mathrm{IV}} 3 \mathrm{~W}_{6}$ was well-dispersed across the mesoporous

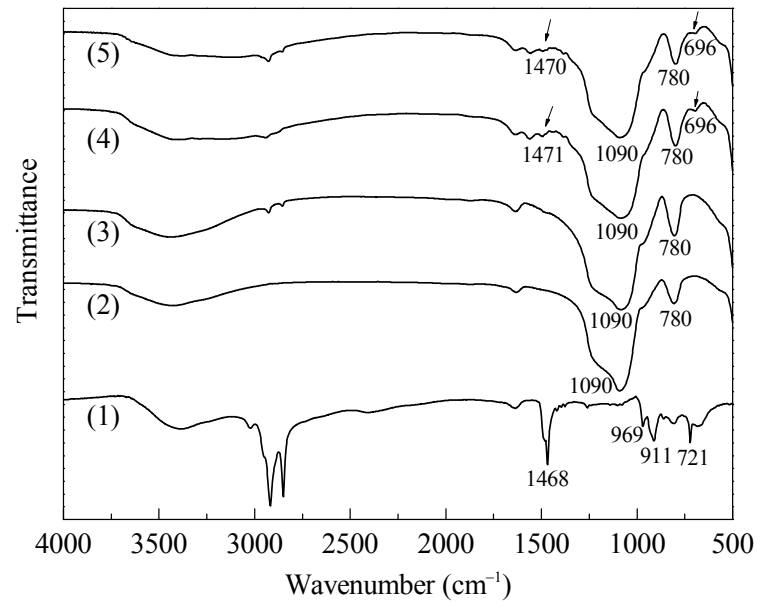

Fig. 1. FTIR spectra of various samples. (1) Catalyst A; (2) MCM-41; (3) MCM-41- $\mathrm{NH}_{2}$; (4) Catalyst B; (5) Catalyst C. 


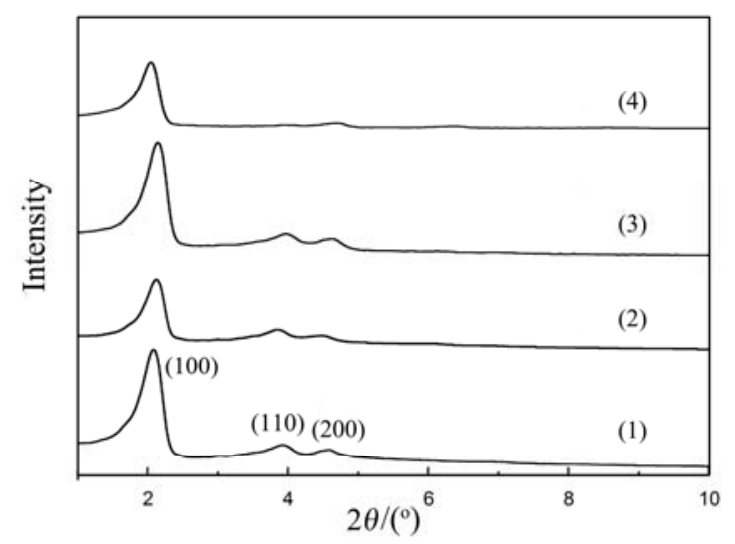

Fig. 2. Small-angle XRD patterns of MCM-41 (1), MCM-41-NH $\mathrm{N}_{2}$ (2), catalyst B (3), and catalyst C (4).

channels. The intensity of the peaks is associated with the degree of crystallinity [55]. The lower intensity demonstrates a decrease in the arrangement of ordered, two-dimensional, hexagonal and mesoporous channels of silica. It reveals that $\mathrm{Q}_{4}-\mathrm{H}_{2} \mathrm{Se}^{\mathrm{IV}} \mathrm{W}_{6}$ was loaded onto the mesoporous channels successfully. This could be caused by interaction between mesoporous silica materials and $\mathrm{Q}_{4}-\mathrm{H}_{2} \mathrm{Se}^{\mathrm{IV}} \mathrm{I}_{3} \mathrm{~W}_{6}$. This result agrees with other reported studies $[55,56]$.

TEM was used to image the porous structure of the synthesized materials, as shown in Fig. 3. It clearly shows the well-ordered, hexagonal arrays of the mesopores typical of MCM-41 materials. The modified samples (MCM-41- $\mathrm{NH}_{2}$ ) also provide well-ordered, hexagonal array structures. The pores of catalyst B were slightly smaller than those of the MCM-41 samples and the channels were less clearly defined. This implies that the $\mathrm{Q}_{4}-\mathrm{H}_{2} \mathrm{Se}^{\mathrm{IV}}{ }_{3} \mathrm{~W}_{6}$ inserted into the pores, but that the mesoporous structure of the support was retained after being impregnated by $\mathrm{Q}_{4}-\mathrm{H}_{2} \mathrm{Se}^{\mathrm{IV}} \mathrm{W}_{3}$. The pore size has clearly changed following the impregnation of $\mathrm{Q}_{4}-\mathrm{H}_{2} \mathrm{Se}^{\mathrm{IV}} \mathrm{V}_{3} \mathrm{~W}_{6}$ in the channels of MCM-41- $\mathrm{NH}_{2}$. The channels of catalyst $\mathrm{C}$ were thinner and less sharply defined than those of MCM-41- $\mathrm{NH}_{2}$, but the mesoporous structure of the support was retained. The TEM images provide strong evidence that $\mathrm{Q}_{4}-\mathrm{H}_{2} \mathrm{Se}^{\mathrm{IV}} \mathrm{V}_{3} \mathrm{~W}_{6}$ was well dispersed in the channels of the mesoporous materials,

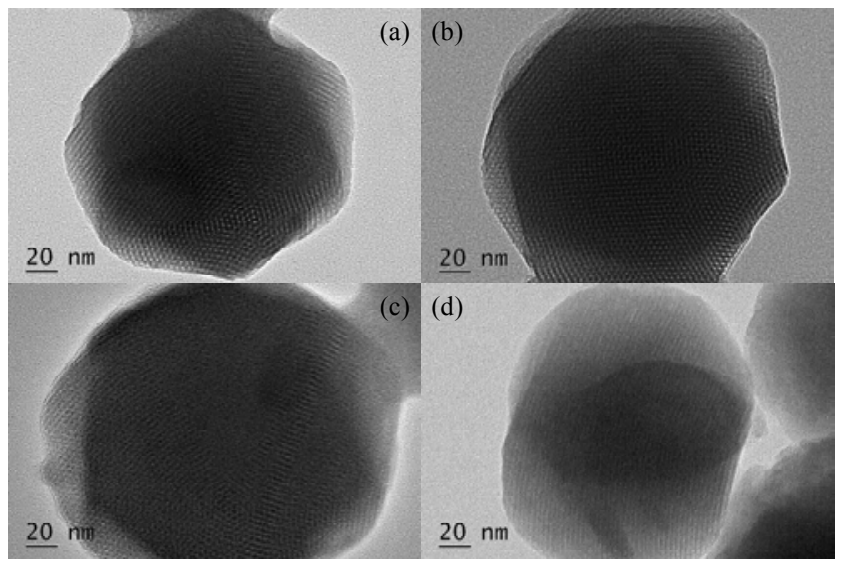

Fig. 3. TEM images of MCM-41 (a), MCM-41-NH2 (b), catalyst B (c), and catalyst $\mathrm{C}(\mathrm{d})$.
Table 1

Surface area and pore volume of mesoporous materials and catalysts.

\begin{tabular}{lcc}
\hline Sample & $A_{\text {BET }}\left(\mathrm{m}^{2} / \mathrm{g}\right)$ & Pore volume $\left(\mathrm{cm}^{3} / \mathrm{g}\right)$ \\
\hline Catalyst A & $<10$ & 0.03 \\
MCM-41 & 647 & 0.76 \\
MCM-41-NH & 324 & 0.31 \\
Catalyst B & 551 & 0.52 \\
Catalyst C & 229 & 0.21 \\
\hline
\end{tabular}

agreeing well with the XRD results.

The measured values of surface area and pore volume for all

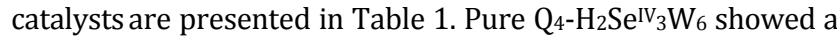
limited surface area $\left(<10 \mathrm{~m}^{2} / \mathrm{g}\right)$ and a small pore volume $(0.03$ $\mathrm{cm}^{3} / \mathrm{g}$ ). The average pore volume of MCM-41 was larger than that of MCM-41-NH2, indicating that the MCM-41 was successfully modified by APTES. As shown in Fig. 4, the internal channels became more complex and smaller after modification. The values for both surface area and pore volume decreased after the two supports (MCM-41 and MCM-41-NH2) were impregnated with $\mathrm{Q}_{4}-\mathrm{H}_{2} \mathrm{Se}^{\mathrm{IV}} \mathrm{W}_{6}$. Considering the low surface area of $\mathrm{Q}_{4}-\mathrm{H}_{2} \mathrm{Se}^{\mathrm{IV}} \mathrm{W}_{6}\left(<10 \mathrm{~m}^{2} / \mathrm{g}\right)$, the decrease of surface area and pore volume was likely caused by small clusters of $\mathrm{Q}_{4}-\mathrm{H}_{2} \mathrm{Se}^{\mathrm{IV}} \mathrm{W}_{6}$ forming in the channels of the mesoporous materials. The data shown in Table 1 confirmed that $\mathrm{Q}_{4}-\mathrm{H}_{2} \mathrm{Se}^{\mathrm{IV}}{ }_{3} \mathrm{~W}_{6}$ was dispersed in the channels of the mesoporous materials.

As mentioned above, simple impregnation of catalyst on mesoporous materials could lead to partial leaching. Therefore, favoring the stability of catalyst, catalyst $\mathrm{C}$ was chosen to conduct the following tests.

\subsection{Effect of reaction conditions on the conversion of DBT}

\subsubsection{Reaction time}

DBT conversion tests were carried out for fuel samples with different sulfur contents. The results are shown in Fig. 5. It is obvious that the conversion of DBT increases with time, though the majority of the conversion completed within $30 \mathrm{~min}$ for each of the tests. Moreover, DBT was almost completely converted (> 99\%) after $180 \mathrm{~min}$. When the sulfur content was raised to $800 \mathrm{ppm}$, the conversion of DBT decreased. As seen from Fig. 5, for model fuels with 500 ppm sulfur content, the conversion of DBT was $98.7 \%$ (approximately the same as the $>99 \%$ required for deep desulfurization) after a reaction time of $120 \mathrm{~min}$. These conditions (500 ppm sulfur content and 120 min reaction time) were chosen for comparative experiments for the desulfurization process using the different catalysts. A similar time was required to achieve deep desulfurization as that reported in the literature [46]. This suggested that the high

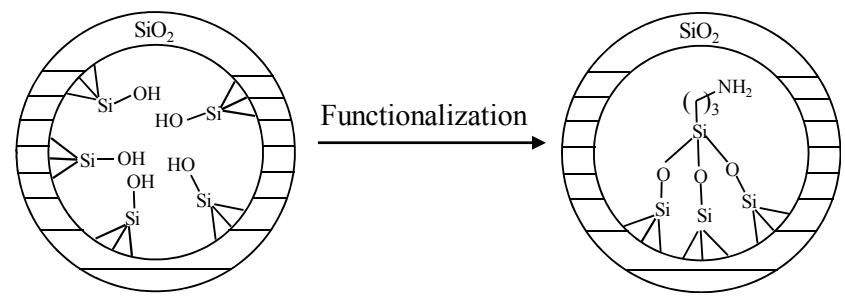

Fig. 4. MCM-41 functionalized by APTES. 


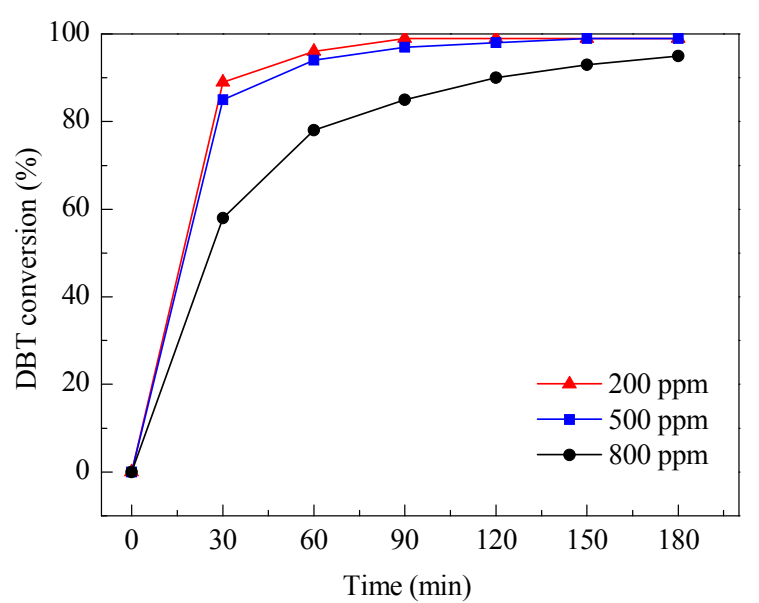

Fig. 5. Influence of reaction time on DBT conversion over catalyst $\mathrm{C}$. Reaction conditions: model fuels $10 \mathrm{~mL}, 318 \mathrm{~K},[\mathrm{O}] /[\mathrm{S}]=2: 1$, catalyst/DBT $=1: 60$.

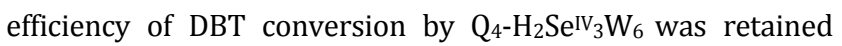
following being impregnated on MCM-41- $\mathrm{NH}_{2}$.

\subsubsection{Reaction temperature}

Fig. 6 shows that at a given reaction time the conversion of DBT was improved by increasing the reaction temperature. When the reaction temperature was elevated from 298 to 318 $\mathrm{K}$, the conversion of DBT reached $90 \%$ within 60 min (compared to $78 \%$ at $298 \mathrm{~K}$ ). The variation between reaction rates at different temperatures suggests a suitable temperature for accelerating reaction needs to be found. According to the Arrhenius equation $\left(K=A \exp ^{-E_{\mathrm{a}} / R T}\right)$ the reaction rate increases exponentially as temperature rises. Although increasing the reaction temperature increases the reaction rate, a tradeoff is needed to decrease energy requirements and to account for other reactions that could occur. For example, elevating the temperature from 318 to $338 \mathrm{~K}$ had little impact on the DBT conversion at $100 \mathrm{~min}$, with this attributed to the fact that the increased temperature could also cause decomposition of $\mathrm{H}_{2} \mathrm{O}_{2}$. This decomposition of $\mathrm{H}_{2} \mathrm{O}_{2}$ decreases the amount of oxidant available and also dilutes the oxidant as water is one of the

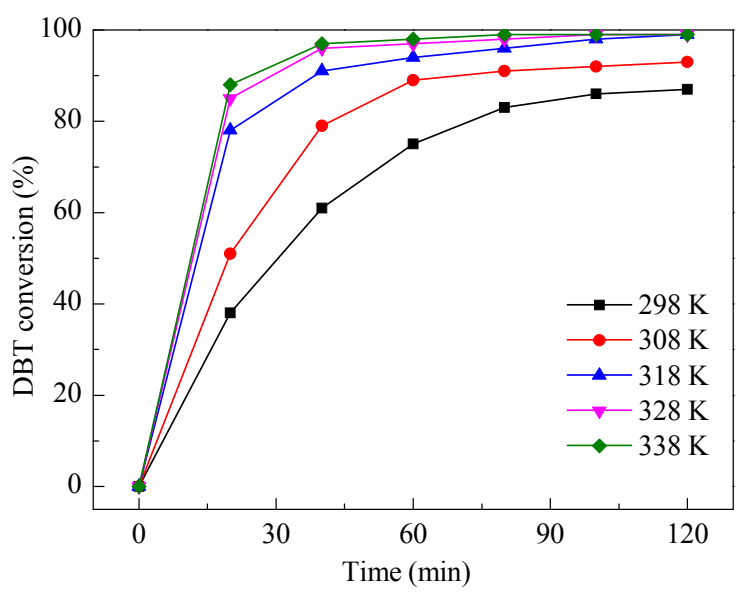

Fig. 6. Effect of temperature on DBT oxidation reaction. Reaction conditions: $500 \mathrm{ppm}$ model fuels $10 \mathrm{~mL},[0] /[\mathrm{S}]=2: 1$, catalyst/DBT = 1:60. decomposition products. In this study, $318 \mathrm{~K}$ was therefore chosen as the most suitable temperature for the desulfurization process, somewhat lower than that used in previously reported work [43].

\subsection{3. $[0] /[S]$ ratio}

In the oxidative system, one of the main factors impacting the conversion is the dosage of oxidant used. The effects of oxidation dosage were studied under different [0]/[S] molar ratios. As seen in Fig. 7, the conversion of DBT quickly increased when $[0] /[\mathrm{S}]$ increased to $2: 1$. However, increasing [0]/[S] further only slightly increased DBT conversion.

According to the stoichiometry of the reaction, $1 \mathrm{~mol}$ DBT would consume $2 \mathrm{~mol} \mathrm{H}_{2} \mathrm{O}_{2}$ and produce 1 mol sulfone $\left(\mathrm{DBTO}_{2}\right)$. As reported elsewhere [57-60], the $\mathrm{H}_{2} \mathrm{O}_{2}$ /sulfur molar ratio is usually $>2$ in the actual reaction process because both oxidation of DBT by $\mathrm{H}_{2} \mathrm{O}_{2}$ and decomposition of $\mathrm{H}_{2} \mathrm{O}_{2}$ simultaneously occur. When $[\mathrm{O}] /[\mathrm{S}]>2$, the diminishing marginal increase in reactivity is attributed to an increase in the thermal decomposition of $\mathrm{H}_{2} \mathrm{O}_{2}$ and dilution effects from water produced from the oxidative reaction. Hence, an excess of $\mathrm{H}_{2} \mathrm{O}_{2}$ was deemed unnecessary and $[0] /[\mathrm{S}]=2$ was chosen for this experiment.

\subsubsection{Catalyst dosage}

To investigate the effect of catalyst amount on the conversion of DBT, a series of experiments with varying amounts of catalyst $\mathrm{C}$ were carried out under the same reaction conditions. The results shown in Fig. 8 indicate that the conversion of DBT sharply increased from $8.3 \%$ to $99.7 \%$ as the molar ratio of catalyst/DBT ranged from 0 to 0.020 . It was found that $98.7 \%$ DBT conversion was obtained when catalyst/DBT $=0.015$. However, further increasing catalyst/DBT up to 0.025 little improved the conversion of DBT. The catalyst/DBT $=0.015$ was the point at which sufficient catalytic sites were available to drive the reaction to completion, and was chosen for further experiments. This catalyst dosage was much lower than that reported elsewhere $[43,46]$, perhaps because the channel structure in the current work increased the number reactive sites.

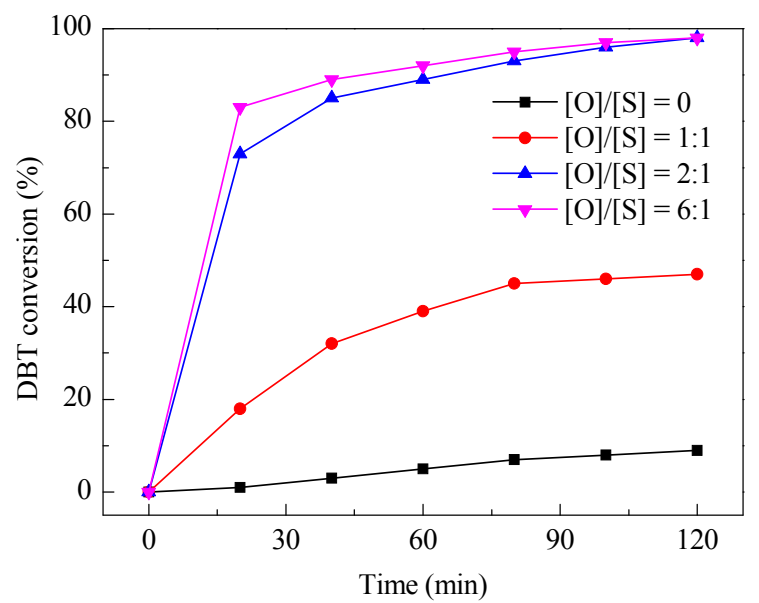

Fig. 7. Impact of $[0] /[\mathrm{S}]$ molar ratio on DBT conversion. Reaction conditions: 500 ppm model fuels $10 \mathrm{~mL}, 318 \mathrm{~K}$, catalyst/DBT = 1:60. 


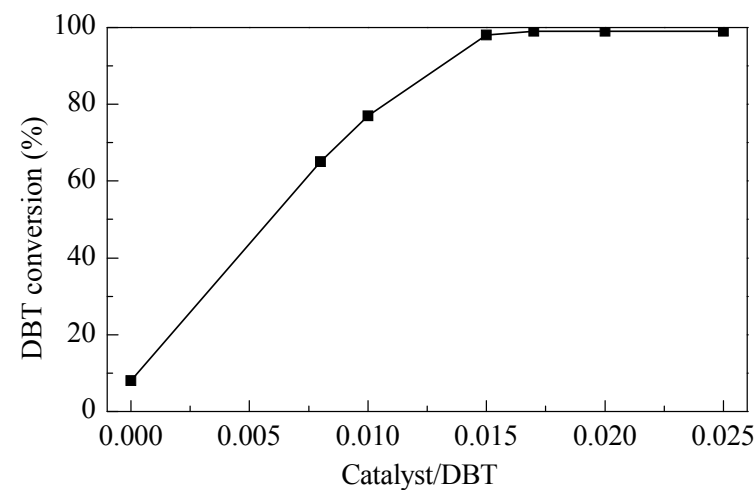

Fig. 8. Effect of catalyst $\mathrm{C}$ dosage on DBT conversion. Reaction conditions: 500 ppm model fuels $10 \mathrm{~mL}, 318 \mathrm{~K},[0] /[\mathrm{S}]=2: 1$.

\subsection{Activity and reusability of the catalysts}

The activity of various catalysts applied to the oxidative desulfurization reaction is compared in Fig. 9. Results for MCM-41 and MCM-41-NH 2 were similar to the control, demonstrating that the mesoporous materials make no or very limited contributions to catalytic activity. Similar results were found in the literature [61,62]. Catalysts A, B, and C all exhibited high and similar catalytic activity with conversion in the range 98.3\%-99.1\%.

Catalysts B and C can be recovered and reused in subsequent catalytic oxidative desulfurization runs. Following the end of a reaction, the used catalysts were separated from the reaction solution, mixed with acetonitrile and stirred for 10 min before being filtered out. This washing was carried out three times, and the catalysts were then pretreated in vacuum oven at $383 \mathrm{~K}$ for $12 \mathrm{~h}$ before being used again.

As seen in Fig. 10, the catalytic efficiency of catalyst $C$ was higher than that of catalyst $B$ through four reaction cycles. This could be due to increased leaching of unstable immobilized $\mathrm{Q}_{4}-\mathrm{H}_{2} \mathrm{Se}^{\mathrm{IV}} \mathrm{V}_{3} \mathrm{~W}_{6}$, causing a reduction in active sites for catalyst $\mathrm{B}$. The activity loss in subsequent reaction cycles could also be attributed to the inactivation of some active sites during the oxidation or recovery processes, which was also more pronounced for catalyst $\mathrm{B}$. The more durable nature of catalyst $\mathrm{C}$ in

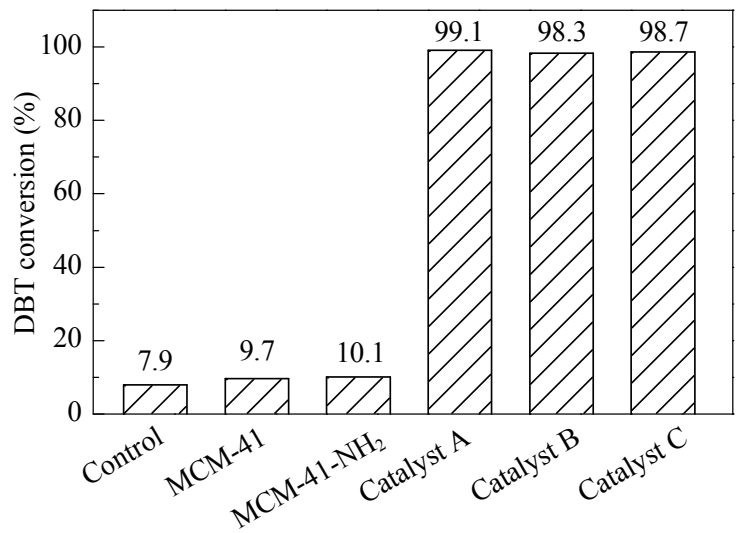

Fig. 9. Performance of three kinds of catalyst on DBT conversion. Reaction conditions: $500 \mathrm{ppm}$ model fuels $10 \mathrm{~mL}, 318 \mathrm{~K},[0] /[\mathrm{S}]=2: 1$, catalyst/DBT $=1: 60$.

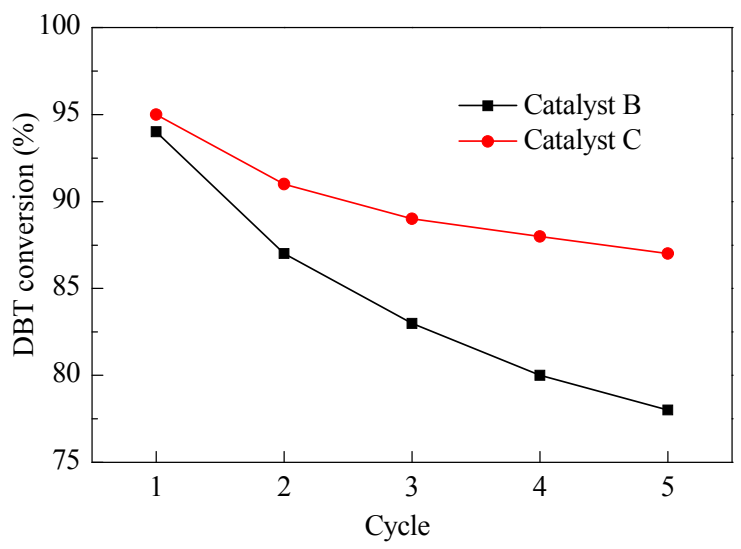

Fig. 10. Impact of recycling supported catalysts on DBT conversion. Reaction conditions: 500 ppm model fuels $10 \mathrm{~mL}, 318 \mathrm{~K},[0] /[\mathrm{S}]=2: 1$, catalyst/DBT $=1: 60$.

the oxidative desulfurization process can be explained as follows. The silanol groups, which are present at the surface and inside the channels of the mesoporous MCM-41, reacted with aminosilane molecules forming $\equiv \mathrm{Si}\left(\mathrm{CH}_{2}\right)_{3} \mathrm{NH}_{3}{ }^{+}$[63]. However, after $\mathrm{Q}_{4}-\mathrm{H}_{2} \mathrm{Se}^{\mathrm{IV}} \mathrm{W}_{6}$ was impregnated on $\mathrm{MCM}-41-\mathrm{NH}_{2}$, the salt $\equiv \mathrm{Si}\left(\mathrm{CH}_{2}\right)_{3} \mathrm{NH}_{3} \cdot \mathrm{H}_{2} \mathrm{Se}^{\mathrm{IV}}{ }_{3} \mathrm{~W}_{6}-\mathrm{Q}_{4}$ was formed instead [64], with the chemical interaction between $\equiv \mathrm{Si}\left(\mathrm{CH}_{2}\right)_{3} \mathrm{NH}_{3}{ }^{+}$and $\mathrm{Q}_{4}-\mathrm{H}_{2} \mathrm{Se}^{\mathrm{IV}}{ }_{3} \mathrm{~W}_{6}$ enhancing the stability of catalyst $\mathrm{C}$.

\subsection{Analysis of oxidation products}

After the reaction, GC-MS and FTIR analysis were carried out on solid products that were formed on the wall of the vessel. GC-MS analysis (Fig. 11) registered $\mathrm{M}^{+}$at $m / z=216$ confirming the presence of the sulfone of DBT. The intense $m / z$ peaks appeared at 187.1 and 168.1 and were attributed to the $\mathrm{C}_{11} \mathrm{H}_{7} \mathrm{SO}$ and $\mathrm{C}_{12} \mathrm{H}_{8} \mathrm{O}$ moieties of DBT $S, S$-dioxide, respectively [65].

As the FTIR results in Fig. 12 show, peaks appeared at 1164 and $1288 \mathrm{~cm}^{-1}$ and were associated with the $\mathrm{O}-\mathrm{S}-0$ symmetric and asymmetric stretching vibrations of $\mathrm{DBTO}_{2}$, respectively.

The acetonitrile phase and the solid product (first dissolved in acetonitrile) were analyzed by GC-FPD. The results shown in

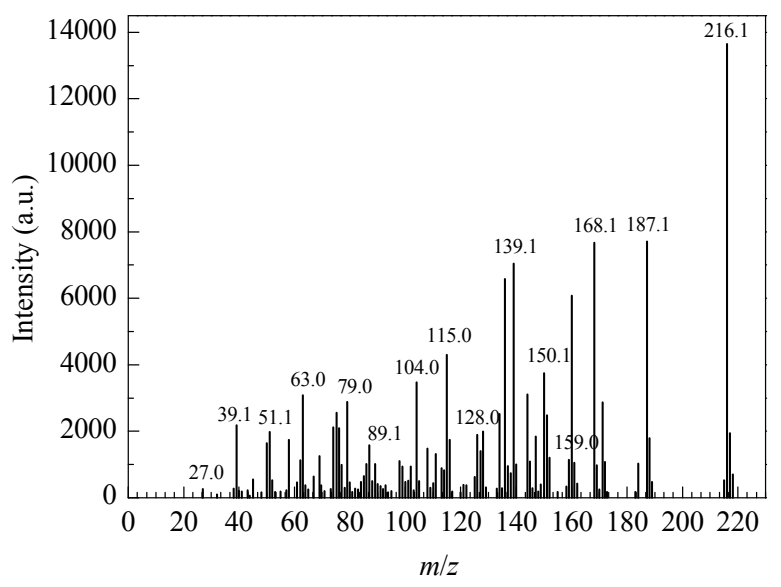

Fig. 11. GC-MS spectrogram for oxidation products present in $n$-octane. 


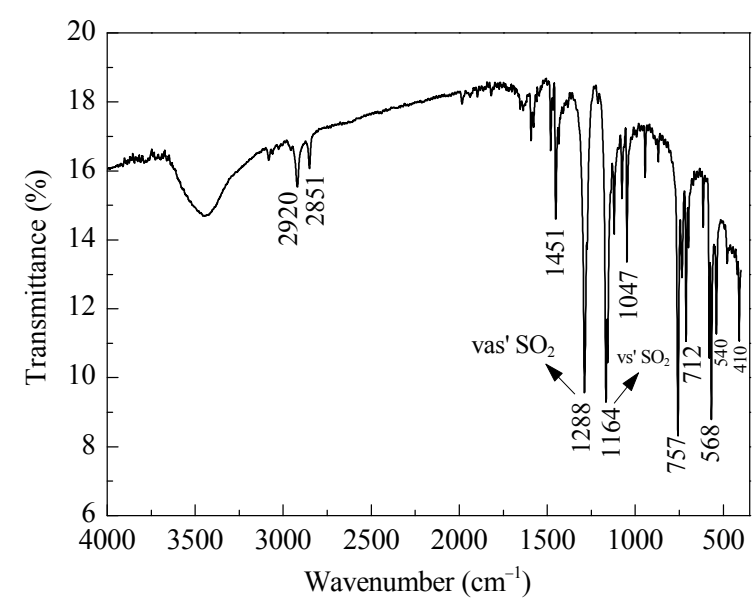

Fig. 12. FTIR spectrum of the solid products formed by the desulfurization reaction.

Fig. 13 demonstrate that the final products in this reaction were mainly $\mathrm{DBTO}_{2}$.

\subsection{Proposed mechanism of the catalytic oxidation}

The results shown in Fig. 7 demonstrate that DBT could be oxidized by the catalyst alone (i.e. without $\mathrm{H}_{2} \mathrm{O}_{2}$ ) with DBT oxidized into sulfoxide or sulfone. In this study, no sulfoxide was detected by GC analysis under reaction conditions. The oxidation of sulfide to sulfoxide is considered fast. So, the mechanism of DBT oxidation in the presence of catalyst $\mathrm{C}$ can be described as the process shown in Fig. 14 and described below.

It could be suggested that the catalyst on the surface of mesoporous silica samples acted as the catalytic active sites in the oxidative desulfurization. However, the oxidation of DBT actually contains two steps. First, the sulfur atom of dibenzothiophene stages a nucleophilic attack on the specific oxygen atom in the catalyst, two protons shift, and the oxygen atom transfers from the catalyst to the dibenzothiophene molecule, forming DBTO or $\mathrm{DBTO}_{2}$ (Fig. 14(i)). Second, the catalyst that lost the oxygen atom contacts with $\mathrm{H}_{2} \mathrm{O}_{2}$, and the peroxide bond regenerates (Fig. 14(ii)). Together these two half reactions complete the oxidization of DBT [66-68].

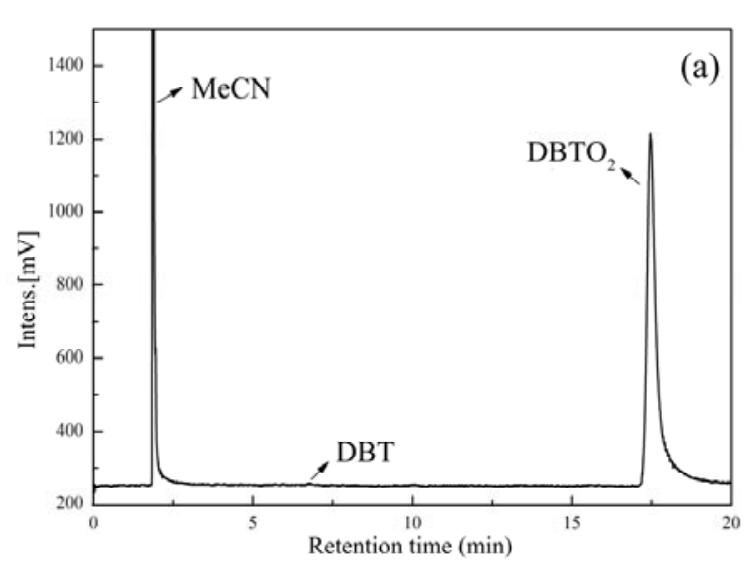

Fig. 13. The megascopic GC-FPD traces of post-reaction acetonitrile phase (a) and the solution of the solid products formed by the desulfurization reaction dissolved in acetonitrile (b).

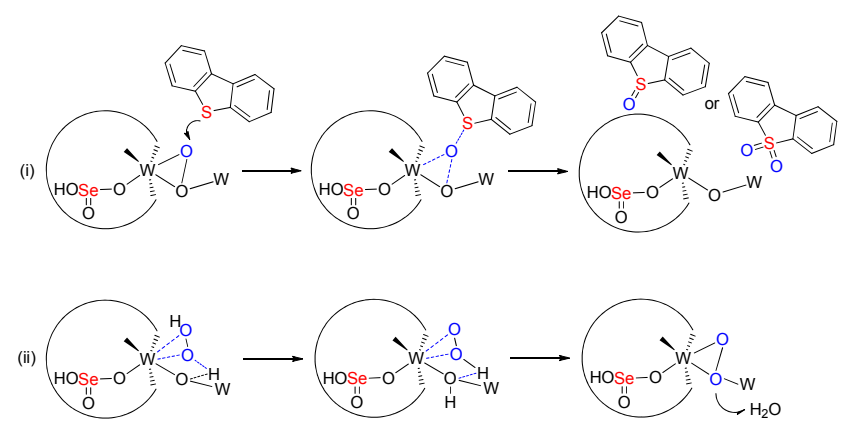

Fig. 14. Mechanism of DBT oxidation.

\section{Conclusions}

Mesoporous materials impregnated with $\mathrm{Q}_{4}-\mathrm{H}_{2} \mathrm{Se}^{\mathrm{IV}}{ }_{3} \mathrm{~W}_{6}$ show effective performance in the oxidative desulfurization at mild reaction conditions. The catalyst $\mathrm{MCM}-41-\mathrm{NH}_{2} / \mathrm{Q}_{4}$ $\mathrm{H}_{2} \mathrm{Se}^{\mathrm{IV}_{3} \mathrm{~W}_{6}}$ showed excellent properties when MCM-41 functionalized by APTES was used as the support structure. The desulfurization reaction achieved a high conversion of DBT at mild conditions $(318 \mathrm{~K})$ with almost all hydrogen peroxide used in the oxidative reaction $([0] /[\mathrm{S}]=2: 1)$. Furthermore, only a small amount of catalyst (catalyst/DBT $=0.015$ ) was required to achieve a high conversion of DBT (98.7\%). The catalyst activity slightly decreased following subsequent reaction cycles though the conversion of DBT remained around $90 \%$ after four rounds of recycling.

Taken together these results demonstrate that the mesoporous material of MCM-41- $\mathrm{NH}_{2}$ impregnated with $\mathrm{Q}_{4}-\mathrm{H}_{2} \mathrm{Se}^{\mathrm{IV}} \mathrm{W}_{3}$ is an excellent catalyst for the oxidative desulfurization system. The present work on the most economical and efficient conditions for the use of $\mathrm{Q}_{4}-\mathrm{H}_{2} \mathrm{Se}^{\mathrm{IV}}{ }_{3} \mathrm{~W}_{6}$ not only solves the problem of recovery and reuse of $\mathrm{Q}_{4}-\mathrm{H}_{2} \mathrm{Se}^{\mathrm{IV}} \mathrm{V}_{3} \mathrm{~W}_{6}$, but also provides a reference for future work in oxidative desulfurization.

\section{Acknowledgments}

The authors wish to acknowledge the financial support provided by the School of Chemistry and Chemical Engineering, Nanjing University.

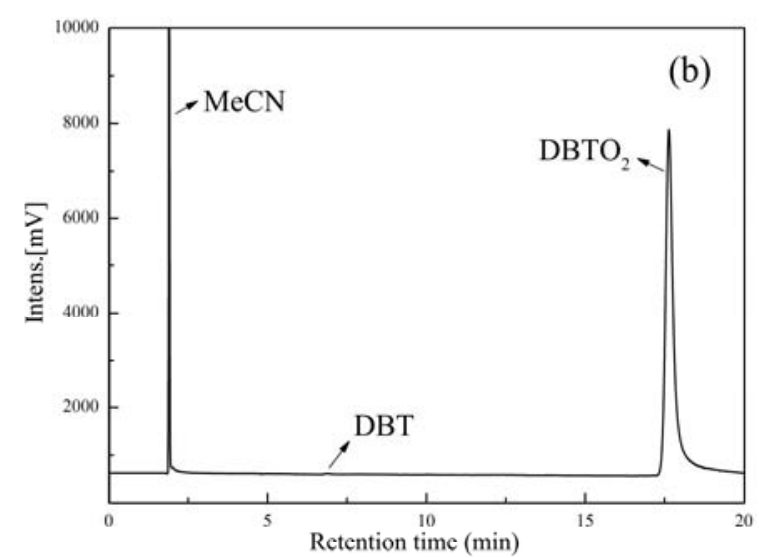




\section{References}

[1] Palomino J M, Tran D T, Hauser J L, Dong H, Oliver S R J. J Mater Chem A, 2014, 2: 14890

[2] Srivastava V C. RSC Adv, 2012, 2: 759

[3] Liu C H, He Q H, Zhang Z, Su Y Y, Xu R F, Hu B X. Chin J Chem, 2014, 32: 410

[4] Tang N F, Zhao X P, Jiang Z X, Li C. Chin J Catal (唐南方, 赵小平, 蒋 宗轩, 李灿. 催化学报), 2014, 35: 1433

[5] Huang C P, Chen B H, Zhang J, Liu Z C, Li Y X. Energy Fuels, 2004, 18: 1862

[6] Ali S H, Hamad D M, Albusairi B H, Fahim M A. Energy Fuels, 2009, 23: 5986

[7] Xiong J, Zhu W S, Ding W J, Yang L, Chao Y H, Li H P, Zhu F X, Li H M. Ind Eng Chem Res, 2014, 53: 19895

[8] Stanislaus A, Marafi A, Rana M S. Catal Today, 2010, 153: 1

[9] Song C S. Catal Today, 2003, 86: 211

[10] Ma X L, Sakanishi K, Mochida I. Ind Eng Chem Res, 1994, 33: 218

[11] Ribeiro S, Barbosa A D S, Gomes A C, Pillinger M, Goncalves I S, Cunha-Silva L, Balula S S. Fuel Process Technol, 2013, 116: 350

[12] Xiao J, Song C S, Ma X L, Li Z. Ind Eng Chem Res, 2012, 51: 3436

[13] García-Gutiérrez J L, Laredo G C, García-Gutiérrez P, Jiménez-Cruz F. Fuel, 2014, 138: 118

[14] Zhu W S, Li H M, Jiang X, Yan Y S, Lu J D, Xia J X. Energy Fuels, 2007, 21: 2514

[15] Zhao D S, Sun Z M, Li F T, Liu R, Shan H D. Energy Fuels, 2008, 22: 3065

[16] Song H, Wan X, Dai M, Zhang J J, Li F, Song H L. Fuel Process Technol, 2013, 116: 52

[17] Derikvand P, Etemadifar Z, Biria D. Int Biodeter Biodegr, 2014, 86: 343

[18] Shu C H, Sun T H, Zhang H B, Jia J P, Lou Z Y. Fuel, 2014, 121: 72

[19] Imtiaz A, Waqas A, Muhammad I. Chin J Catal (催化学报), 2013, 34: 1839

[20] Ban L L, Liu P, Ma C H, Dai B. Chin Chem Lett, 2013, 24: 755

[21] Chamack M, Mahjoub A R, Aghayan H. Chem Eng J, 2014, 255: 686

[22] Fang D W, Wang Q, Liu Y, Xia L X, Zang S L. Energy Fuels, 2014, 28 6677
[23] Jiang Z X, Lü H Y, Zhang Y N, Li C. Chin J Catal (蒋宗轩, 吕宏缨, 张 永娜, 李灿. 催化学报), 2011, 32: 707

[24] Zhang G F, Yu F L, Wang R. Petroleum Coal, 2009, 51: 196

[25] Campos-Martin J M, Capel-Sanchez M C, Perez-Presas P, Fierro J L G. J Chem Technol Biotechnol, 2010, 85: 879

[26] Zheng H W, Sun Z, Chen X L, Zhao Q, Wang X H, Jiang Z J. Appl Catal A, 2013, 467: 26

[27] Chan N Y, Lin T Y, Yen T F. Energy Fuels, 2008, 22: 3326

[28] Sundararaman R, Ma X L, Song C S. Ind Eng Chem Res, 2010, 49: 5561

[29] Xiao J, Wu L M, Wu Y, Liu B, Dai L, Li Z, Xia Q B, Xi H X. Appl Energy, 2014, 113: 78

[30] Abdalla Z E A, Li B S. Chem Eng J, 2012, 200-202: 113

[31] Te M, Fairbridge C, Ring Z. Appl Catal A, 2001, 219: 267

[32] Zhang J, Wang A J, Wang Y J, Wang H Y, Gui J Z. Chem Eng J, 2014, 245: 65

[33] Li C, Jiang Z X, Gao J B, Yang Y X, Wang S J, Tian F P, Sun F X, Sun X P, Ying P L, Han C R. Chem Eur J, 2004, 10: 2277

[34] Mei H, Mei B W, Yen T F. Fuel, 2003, 82: 405

[35] Wan M W, Yen T F. Appl Catal A, 2007, 319: 237

[36] Zhang M, Zhu W S, Xun S H, Li H M, Gu Q Q, Zhao Z, Wang Q. Chem Eng J, 2013, 220: 328

[37] Zhu W S, Wu P W, Yang L, Chang Y H, Chao Y H, Li H M, Jiang Y Q, Jiang W, Xun S H. Chem Eng J, 2013, 229: 250

[38] Shan J H, Chen L, Sun L B, Liu X Q. Energy Fuels, 2011, 25: 3093

[39] Zhu W S, Xu Y H, Li H M, Dai B L, Xu H, Wang C, Chao Y H, Liu H. Korean J Chem Eng, 2014, 31: 211

[40] Luo G Q, Kang L H, Zhu M Y, Dai B. Fuel Process Technol, 2014, 118: 20

[41] Zhu W S, Zhu G P, Li H M, Chao Y H, Zhang M, Du D L, Wang Q, Zhao Z. Fuel Process Technol, 2013, 106: 70

[42] Li B S, Ma W, Liu J J, Han C Y, Zuo S L, Li X F. Catal Commun, 2011, 13: 101

[43] Li J L, Hu B, Tan J J, Zhuang J Z. Transit Metal Chem, 2013, 38: 495

[44] Nowiǹska K, Kaleta W. Appl Catal A, 2000, 203: 91

[45] Verhoef M J, Kooyman P J, Peters J A, Van Bekkum H. Microporous Mesoporous Mater, 1999, 27: 365

[46] Hu Y W, He Q H, Zhang Z, Ding N D, Hu B X. Chem Commun, 2011,

\section{Graphical Abstract}

Chin. J. Catal., 2015, 36: 1205-1213 doi: 10.1016/S1872-2067(15)60897-X

Oxidative desulfurization of dibenzothiophene catalyzed by peroxotungstate on functionalized MCM-41 materials using hydrogen peroxide as oxidant

Dong Xie, Qihui He, Yangyang Su, Tongwei Wang, Renfu Xu, Baixing Hu* Nanjing University
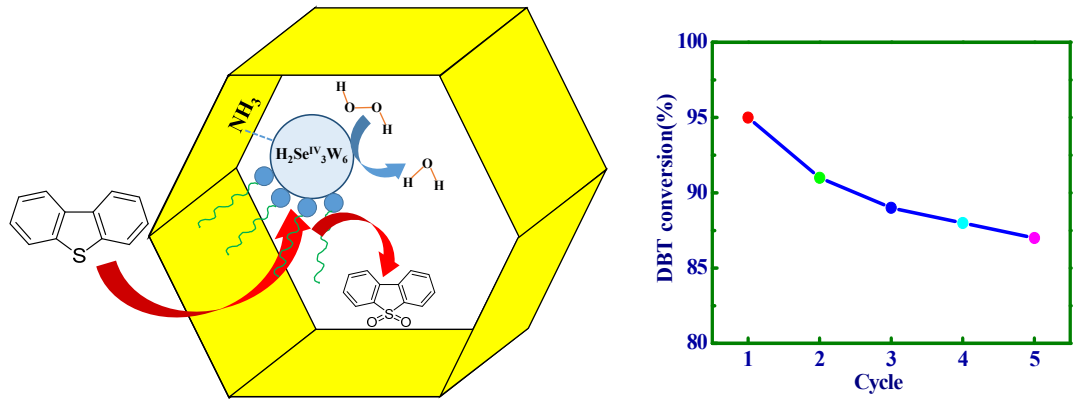

In the oxidative desulfurization of dibenzothiophene (DBT), peroxotungstate was supported on functionalized MCM-41 mesoporous molecular sieves. The supported catalyst shows a highly catalytic ability and it also has a good reusability. 
47: 12194

[47] Kresge C T, Leonowicz M E, Roth W J, Vartuli J C, Beck J S. Nature, 1992, 359: 710

[48] Roik N V, Belyakova L A.J Solid State Chem, 2014, 215: 284

[49] Corma A. Chem Rev, 1997, 97: 2373

[50] Johnson B J S, Stein A. Inorg Chem, 2001, 40: 801

[51] Marme F, Coudurier G, Védrine J C. Microporous Mesoporous Mater, 1998, 22: 151

[52] Ishimoto R, Kamata K, Mizuno N. Angew Chem Int Ed, 2009, 48: 8900

[53] Hulea V, Fajula F, Bousquet J. J Catal, 2001, 198: 179

[54] Lü H Y, Gao J B, Jiang Z X, Yang Y X, Song B, Li C. Chem Commun, 2007: 150

[55] Blasco T, Corma A, Martínez A, Martínez-Escolano P. J Catal, 1998, 177: 306

[56] Lim M H, Blanford C F, Stein A. Chem Mater, 1998, 10: 467

[57] Xiong J, Zhu W S, Ding W J, Yang L, Zhang M, Jiang W, Zhao Z, Li H M. RSC Adv, 2015, 5: 16847

[58] Li H M, Zhu W S, Wang Y, Zhang J T, Lu J D, Yan Y S. Green Chem,
2009, 11: 810

[59] Ding W J, Zhu W S, Xiong J, Yang L, Wei A M, Zhang M, Li H M. Chem Eng J, 2015, 266: 213

[60] Zhu W S, Li H M, Jiang X, Yan Y S, Lu J D, Xia J X. Energy Fuels, 2007, 21: 2514

[61] Al-Shahrani F, Xiao T C, Llewellyn S A, Barri S, Jiang Z, Shi H H, Martinie G, Green M L H. Appl Catal B, 2007, 73: 311

[62] Jiang X, Li H M, Zhu W S, He L N, Shu H M, Lu J D. Fuel, 2009, 88: 431

[63] Bordoloi A, Lefebvre F, Halligudi S B. J Catal, 2007, 247: 166

[64] Kaleta W, Nowińska K. Chem Commun, 2001: 535

[65] Bowie J H, Williams D H, Lawesson S O, Madsen J, Nolde C, Schroll G. Tetrahedron, 1966, 22: 3515

[66] Duncan D C, Chambers R C, Hecht E, Hill C L. J Am Chem Soc, 1995, 117: 681

[67] Antonova N S, Carbó J J, Kortz U, Kholdeeva O A, Poblet J M. J Am Chem Soc, 2010, 132: 7488

[68] Kamata K, Hirano T, Ishimoto R, Mizuno N. Dalton Trans, 2010, 39: 5509

\title{
MCM-41分子篮负载亚硒核过氧钨酸盐催化剂催化二苯并噻吩氧化脱硫
}

\author{
谢 东, 何其慧, 苏阳洋, 王童薇, 许仁富, 胡柏星 ${ }^{*}$
}

南京大学化学化工学院, 江苏省机动车尾气污染控制重点实验室, 江苏南京210093

摘要: 石油在作为燃料使用过程中常常产生各种污染, 特别是油品中的含硫化合物不仅会降低油品品质, 而且燃烧后产生的硫氧 化物可污染大气, 形成酸雨, 危害人类健康. 因此, 油品深度脱硫是一项十分重要而紧迫的工作.

目前油品脱硫方法有很多种, 主要分为加氢脱硫与非加氢脱硫. 加氢脱硫反应条件苛刻, 脱硫效率低, 对设备要求高, 因而非 加氢脱硫正在被广泛研究. 其中氧化脱硫反应条件温和, 脱硫效率高, 对设备要求不高, 有望实现规模化应用. 在氧化脱硫反应 中, 催化剂是研究重点, 尤其是催化剂效率及可回收能力. 本课题组合成的亚硒核过氧铇酸盐是一种具有高选择性和高催化活性 的催化剂, 但它在反应后无法实现回收再利用, 从而限制了其广泛应用. 为了提高该催化剂的可回收能力, 本文尝试制备负载型 亚硒核过氧钨酸盐用于氧化脱硫反应中, 考察其催化效率及可回收能力.

分子笁具有孔结构, 比表面积大且较为稳定, 是理想的催化剂载体. 本文采用浸渍法制备了MCM-41分子笁负载的亚硒核过 氧铇酸盐, 为了提高负载能力, 减少催化剂溶脱, 还制备了MCM-41- $\mathrm{NH}_{2}$ 分子篮负载的亚硒核过氧铇酸盐, 并运用红外光谱、X射线 衍射、 $\mathrm{N}_{2}$ 吸附-脱附和透射电镜对它们进行了表征. 结果显示, 亚硒核过氧铇酸盐在MCM-41和MCM-41- $\mathrm{NH}_{2}$ 分子篮内分散均匀, 表明负载成功. 将负载型亚硒核过氧铇酸盐催化剂用于模拟油样二苯并噻吩(DBT)氧化脱硫实验, 并用气相-火焰光度检测仪跟 踪实验. 结果表明, 负载型和非负载型催化剂均具有较高的催化性能. 模拟油样在负载型催化剂作用下氧化脱硫反应 $2 \mathrm{~h}$ 后, DBT 转化率达 $98.7 \%$, 实现了深度脱硫. 此外, 还优化了反应时间、反应温度及氧化剂和催化剂用量. 与其它催化剂相比, 在相似脱硫效 率情况下, 负载型催化剂的催化效率更高, 反应条件更加温和, 催化剂用量更少, 因而更加环保和节能. 对反应产物进行了红外光 谱、气相-质谱联用分析以及气相色谱保留时间对比分析, 结果表明DBT脱硫反应产物为 $\mathrm{DBTO}_{2}$. 结合相关文献, 对该催化剂上 DBT氧化脱硫提出了一种可能的催化氧化反应机理.

反应后将负载型催化剂回收过滤, 洗涤和干燥后, 进行下一轮氧化脱硫反应. 结果表明, MCM-41分子篮负载的亚硒核过氧铇 酸盐在循环使用过程中, DBT转化率下降较快, 循环使用 4 次后, DBT转化率降至 $80 \%$, 而MCM- $41-\mathrm{NH}_{2}$ 分子篮负载的催化剂在循 环使用4次后, DBT转化率仍达 $90 \%$. 这表明MCM-41- $\mathrm{NH}_{2}$ 分子篮负载的亚硒核过氧铇酸盐催化剂具有更好的稳定性和回收使用 性能.

综上所述, 负载型亚硒核过氧铇酸盐是一种高效的氧化脱硫催化剂, 在较为温和的反应条件下即可实现深度催化氧化脱硫, 其循环使用性能也得到明显提高. 本结果可为该催化剂未来在工业上广泛应用提供一定参考.

关键词: 二苯并噻吩; 氧化脱硫; 亚硒核过氧铇酸盐; MCM-41分子篮

收稿日期: 2015-01-29. 接受日期: 2015-05-20. 出版日期: 2015-08-20.

*通讯联系人. 电话/传真: (025)83592878; 电子信箱: hubx@nju.edu.cn

基金来源：国家基础科学人才培养基金(J1103310).

本文的英文电子版由Elsevier出版社在ScienceDirect上出版(http://www.sciencedirect.com/science/journal/18722067). 